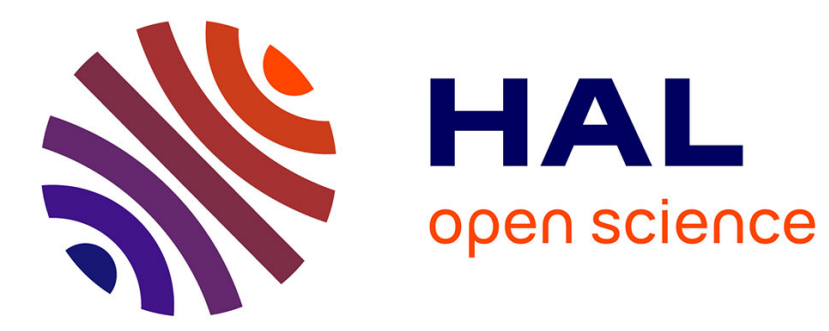

\title{
Geometrical Features of Dislocations Gliding on non-compact Planes in Al-Zn Single Crystal
}

\author{
Patrick Anongba, Joel Bonneville, J.-L. Verger-Gaugry
}

\section{To cite this version:}

Patrick Anongba, Joel Bonneville, J.-L. Verger-Gaugry. Geometrical Features of Dislocations Gliding on non-compact Planes in Al-Zn Single Crystal. Scripta Metallurgica, 1987, 21 (6), pp.777-782. 10.1016/0036-9748(87)90321-8 . hal-03133814

\section{HAL Id: hal-03133814 https://hal.science/hal-03133814}

Submitted on 17 Feb 2021

HAL is a multi-disciplinary open access archive for the deposit and dissemination of scientific research documents, whether they are published or not. The documents may come from teaching and research institutions in France or abroad, or from public or private research centers.
L'archive ouverte pluridisciplinaire HAL, est destinée au dépôt et à la diffusion de documents scientifiques de niveau recherche, publiés ou non, émanant des établissements d'enseignement et de recherche français ou étrangers, des laboratoires publics ou privés. 


\title{
Geometrical features of dislocations gliding on
} non-compact planes in Al-Zn single crystal

\author{
P. Anongba ${ }^{\dagger}$, J. Bonneville ${ }^{\dagger}$ and J.-L. Verger-Gaugry ${ }^{\ddagger} \dagger$, \\ ${ }^{\dagger}$ Ecole Polytechnique Fédérale de Lausanne, IGA, 1015 Lausanne, Ecublens, Switzer- \\ land. \\ ${ }^{\dagger}$ LTPCM/ENSEEG/INPG (CNRS UA 29), BP 75, Domaine Universitaire, 38402 Saint \\ Martin d'Hères, France
}




\section{INTRODUCTION}

The creep characteristics of the alloy Al-11 wt $\mathrm{zn}$ have been extensively studied in the solid solution range above $190^{\circ} \mathrm{C}$. A pure metal like behaviour is exhibited, i.e. a subgrain structure is present during stage II of creep (constant strain rate) and the activation energy and activation area of the creep rate are very close to those in pure aluminium $[1,2,3]$.

A detailed study of the creep substructure and the associated internal stresses has been undertaken in this alloy in an attempt to determine the rate controlling mechanism of creep [4, 5]. In this study, the local stresses have been measured through the radius of curvature of the dislocations. Defect configurations representative of the loaded state were obtained by pinning the dislocations at the end of the creep test [4] (see $\mathbf{S} 2.2$ below).

In the present study, single crystals of the same alloy were grown by the strain anneal technique. They were creep tested in stage I and the dislocation substructures, which were pinned under load, were then observed by Transmission Electron Microscopy. The following two points have been investigated:

- the gecmetrical features of dislocations gliding on non-compact planes (glide planes, shapes, evidence of deviation) correlated with the possible mechanism of glide on non-compact planes.

- the technique of evaluating local stresses from the radii of curvature of dislocations using the Dewit-Koehler line tension formulation [6].

In the line tension model, the local shear stress $\tau_{e}$, the radius of curvature of dislocations $\rho$ and the line tension $T$ are related in the following way: $\tau e=T / b \rho(1)$, where $b$ is the Burgers vector of the dislocation. According to Dewit and Koehler, the line tension is defined as : $\mathrm{T}(\alpha)=\mathrm{E}(\alpha)+\mathrm{d}^{2} \mathrm{E} / \mathrm{d} \alpha^{2}(2)$, where $\mathrm{E}(\alpha)$ is the line energy of an inf inite, straight dislocation of character $\alpha$.

Experimentally, the line tension model has rarely been tested because direct analysis of the equilibrium shapes of dislocations under stress requires either the pinning of dislocations under load [7] or in situ deformation experiments in the high voltage of electron microscope $[8]$. Thus, the second purpose of this study was to investigate the experimental validity of the line tension model.

\section{EXPERIMENTAL TECHNIQUES}

\subsection{Production of $\mathrm{Al}-11$ wt $\mathrm{z}$ in single crystals}

Single crystals were grown by the strain anneal technique. In this technique, a sample is plastically deformed at room temperature and subsequently annealed at high temperature. With this procedure, the sample acquires the capacity for renewing its texture. This occurs as a result of nucleus formation followed by the consumption of the old grains by the new ones. For a critical plastic deformation, crystals of maximum size can be obtained [9].

The polycrystalline alloy used was provided by Alusuisse in the form of extruded bars $8 \mathrm{~mm}$ in diameter. These bars were then rolled into foils $2 \mathrm{~mm}$ in thickness. Samples having a tapered shape were machined from the foils, as shown in Fig. 1. These samples were annealed for 72 hours at $450{ }^{\circ} \mathrm{C}$ under argon to homogenize their composition, resulting in an initial grain size of about $0.5 \mathrm{~mm}$ (Fig. 2). They were then plastically deformed in tension with an Instron machine to failure at room temperature.

Because of the tapered shape, the deformation varies continuously along sample axis and the critical strain is achieved within the tapered shape. 
The recrystallization is performed in a moving furnace in an argon atmosphere. The furnace temperature is $600^{\circ} \mathrm{C}$ and it moves at a speed of $6 \mathrm{~mm} /$ hour. The gradient of the temperature is about $4^{\circ} \mathrm{C} / \mathrm{mm}$. After recrystallization, large grains $\left(15 \times 7 \mathrm{~mm}^{2}\right.$ on average) elongated in the direction of the tensile axis appear in the middle of the samples. Tensile specimens were then obtained by spark machining with the possibility of choosing the tensile axis in the plane of sample faces (Fig. 3).

\subsection{Creep techniques and pinning of dislocations}

The creep tests were performed at $250^{\circ} \mathrm{C}$ under a helium atmosphere, at a constant stress of 4.7 MPa and up to 18 strain. The specimen elongation was measured with a precision of about 1 in for a gauge length of $10 \mathrm{~mm}$. The specimen tensile axis was of the [112] type. The pinning technique consists of rapidly cooling the specimen under load at sane point during the creep test and subsequently aging it [4]. The zinc precipitates and dislocation structures formed during the creep process are preserved. With this technique, it has been shown that local effective stresses higher than $24 \mathrm{MPa}$ can be measured at room temperature for non-edge dislocations [4].

2.3. Observation of dislocations pinned under load

The microscope used was a Hitachi $\mathrm{H} 700 \mathrm{H}$ operating at $200 \mathrm{kV}$. Thin foils were prepared by first cutting discs $0.3 \mathrm{~mm}$ thick parallel to one of the two primary (111) slip planes by spark machining (Fig. 4) and then electropolished by the jet technique using a solution $338^{\mathrm{HNO}_{3}-678}$ $\mathrm{CH}_{3} \mathrm{OH}$ at $-20{ }^{\circ} \mathrm{C}$ and $20 \mathrm{~V}$.

The Burgęrs vector $\vec{b}$ of the dislocations was dețermined using two different diffrac-

tion vectors, $\vec{g}$, satisfying the invisibility principle $\vec{g} \cdot \vec{b}=0$.

The dislocation plane was determined by :

- $\vec{b}$ and the direction defined by two points on the dislocation,

- three different points on the dislocation,

- comparing different shapes of the dislocation in the principal planes having $b$ as zone axis.

\subsection{Local effective stresses measurements}

The local effective stress $\tau_{e}$ can be written: $\tau_{e}=\tau_{a}-\tau_{1}-\tau_{f}(3)$, where $\tau_{a}$ is the applied shear stress, $\tau_{i}$ the internal stress and $\tau_{f}$ the friction force.

With the small strain imposed on the specimens it can be assumed that the internal stress $\tau_{i}$ is negligible on isolated dislocations.

Considering that the friction force on compact planes of aluminium is negligible, the local effective stress should be close to the applied shear stress, giving an experimental line tension $\mathrm{T}_{\mathrm{a}}=\mathrm{bp}_{\mathrm{a}}$, where $\rho$ is the measured mean value of the radius of curvature.

In order to compare the applied shear stress with the theoretical expression given by Dewit and Koehler, the value of $\mathrm{E}(\alpha)$ was calculated using isotropic elasticity theory : $\mathrm{E}(\alpha)=$ $\left.\left(\mu \mathrm{b}^{2} / 4 \pi\right)\left(\left[1-\nu \cos ^{2} \alpha\right] / 1-v\right]\right) \ln \left(R / r_{0}\right)$ (4) where $R$ and $r_{0}$ are the outer and inner cut of $f$ radii of the dislocations respectively; $R$ is taken equal to $\rho$ and $r_{0}$ to $b ; \alpha$ is the character of the straight segment joining two points of the curved dislocation between which the radius of curvature is measured. $\nu$, the Poisson ratio of aluminium is taken equal to $1 / 3 . \mu$ is the shear modulus of aluminium; its variation with the temperature can be deduced from Young's modulus, $\mathrm{E}$ $[10]$ : $-\mathrm{dE} / \mathrm{Ed}=0.43 \times 10^{-3}\left[\mathrm{~K}^{-1}\right](5)$.

\section{(a) Geometrical features of dislocations}

- Evidence of deviation between compact and non-compact planes

Fig. 5 shows a dislocation $(A, I, B)$ having the Burgers vector $B=1 / 2[\overline{1} 10]$. The directions of $(A, I),(I, B)$ and $b=1 / 2[110]$ are shown in Fig. 4. The portion $(I, B)$ is in the plane (111) and the portion $(A, I)$ is in either the (112) or (113) plane. The micrographs demonstrate the following features :

1) Evidence of deviation is noticeable in Fig. 5d where there is a change in curvature between the portions $(A, I)$ and $(I, B)$ at the point $I$.

2) The direction of $(A, I)$ is close to $\vec{b}=1 / 2[\overline{1} 10]$ (Fig. 4), so the plane of $(A, I)$ could be (112), (113) or perhaps (111) or (001). We rule out the (001) plane because the portion $(A, I)$ is not straight in fig. Sd for an incident beam direction parallel to [110]. Upon tilting the specimen to the $[110]$ zone axis, we observe a decrease in the curvature of segment (A,I), as show in fig. 5d. Bowever, the curvature of this portion does not decrease when viewed in the [113] direction (fig. 5c). Noting that the thin foil face is (111), the plane of the dislocation (A,I) can not be (111); but rather it is probably (112) or (113).

- Shape of screw dislocations 
A rectilinear screw dislocation (more than 8 um long) is shown in Fig. 6. Such screw dislocations are isolated and uniformly distributed in the thin foils.

- Curved dislocations in non-compact planes with a straight screw portion

Fig. 7 shows a dislocation $(A, B, C, D)$ having the Burgers vector $b=1 / 2[1 \overline{10}]$. The stereographic projection, fig. 4, shows the directions $(B, A),(C, D),(C, B)$ and $\left[\frac{1}{10}\right]$. The plane formed by these directions is either (112) or (113). A camon feature for all the dislocations in these non-compact planes is that the screw portion of the dislocations is straight.

(b) Measured local effective stresses

Table 1 gives the results obtained for three dislocation characters: 25,35 and 45 degrees. About ten dislocatinns have been analysed for each character and the mean values are presented in Table 1. Examples of the three classes of dislocations ( $\alpha=25,35$ and 45 deg.) are given below:

- portion (A,I), fig. 5b: plane (112); $\alpha=25^{\circ} ; \rho=4.5 \mu \mathrm{m} ; \tau_{\mathrm{a}}=2 \mathrm{MPa} ; \tau_{\mathrm{e}}=2 \mathrm{MPa}$.

- portion (C,D), fig. 7a: plane (112); $\alpha=35^{\circ} ; \rho=4$ um; $\tau_{a}=2 \mathrm{MPa} ; \tau_{\mathrm{e}}=2 \mathrm{MPa}$.

- portion (a,b); fig. 8: plane (111); $\alpha=45^{\circ} ; \rho=2.8 \mu \mathrm{m} ; \tau_{\mathrm{a}}=1.9 \mathrm{MPa} \tau_{\mathrm{e}}=2.2 \mathrm{MPa}$.

\section{DISCUSSION AND CONCLUSION}

In the present study, in addition to the two symetric and primary glide systems, i.e. [110](111) and [011] (111) (fig. 4), systems of the type $[110](112)$ or $[110](113)$ are also activated. Most of the observed dislocations have Burgers vectors [110] or [011], but they are not necessarily in (111) type planes. The precision of our measurements does not allow us to distinguish whether these dislocations lie in the (112) or (113) planes.

The presence of non-compact glide in pure $F O C$ metals has been known for a long time. It was first observed in aluminium $[11,12]$ and then in others metals (silver, copper, nickel and gold) [13]. Previous studies suggested that there exists a mechanism of deviation between compact and non-compact planes $[12,13]$.

A unique aspect of the substructure is the observation of long, straight screw dislocations. Curved dislocations in the (112) or (113) planes exhibit a straight screw portion. This suggests a lower mobility of the screws as compared to the edges on non-compact planes. In addition, the local effective stress calculated for the non-screw portions using the Dewit and Koehler expression, is close to the applied, resolved shear stress. Therefore, only screw dislocations are subjected to a friction force. This conclusion indicates that the glide velocity in these non-compact planes is controlled by the movement of the screw dislocations.

The observation of straight screw segments is a strong experimental evidence suggesting that the movement in these non-compact planes occurs by the thermally activated nucleation and propagation of kink pairs along the screw dislocations dissociated on $\{111\}$ type planes. Since the density of screw dislocations far exceeds that of non-screw dislocations in the subgrain interiors [4], this mechanism could control the creep rate. This mechanism had been derived by Escaig for prismatic glide in hexagonal close packed metals [14]. It has been suggested to operate for (110) glide in FOC metals [15] and confronted to experiments for $\{112\}$ and $\{001\}$ glide in aluminium by couret [16] and Carrard [17] respectively.

The line tension model in the complete formulation of Dewit and Koehler gives local effective stresses close to the applied shear stress in the measured range of curvatures ( 3 im and larger). Therefore, it is not necessary to take account of the mutual interactions of the dislocation segments on the curved dislocation for radii of curvature greater than or equal to 3 , m when computing local stresses.

ACKNOWLEDGEMPNIS The authors would like to thank Prof. J.L. Martin for suggesting this study and for discussions of the results, Dr M. Carrard and Dr M.J. Mills for valuable comments on the article.

\section{REFERENCES}

[1] G. König and w. Blum, Acta Met. 25, 1531 (1977).

2. C. Young, S. Robinson and O.D. Sherby, Acta Met. 23, 633 (1975).

[3] W. Blum, A. Absenger and R. Feilhauer, Strength of Metals and Alloys, Edit. P. Haasen, V. Gerold and G. Kostorz, Vol. 1, p. 265, Pergamon, (1979).

[4] M. Morris and J.L. Martin, Acta Met. 32, 549 (1984).

5. M. Morris and J.L. Martin, Acta Met. 32, 1609 (1984).

6] G. Dewit and J.S. Koehler, Phys. Rev. 116, 1113 (1959).

7 P. Anongba, Travail pratique de diplôme, IGA, EPFL, Lausanne (1984).

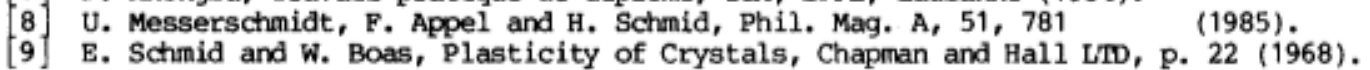


[10] J. Friedel, Dislocations, Pergamon Press, p. 454, Paris (1964).

11. E. Schmid and W. Boas, z. Physik. 71, 703 (1931).

12. P. Lacombe and L. Beaujard, J. Inst. Met. 74, 1 (1947).

13. R. Le Hazif, P. Dorizzi and J.P. Poirier, Acta Met., 21, 903 (1973).

14. B. Escaig, Phys. Stat. Sol. 28, 463 (1968).

[15] G. Vanderschaeve and B. Bscaig, in "Dislocations et Déformation Plastique" Edit. P. Groh, L.P. Kubin and J.L. Martin, Les Editions de Physique, Orsay, p. 141 (1980).

[16] A. Couret, Thèse 3ème cycle, Toulouse (1985).

[17] M. Carrard, EPFL, Thèse no 595 (1985), to be published in Phil. Mag (1987).

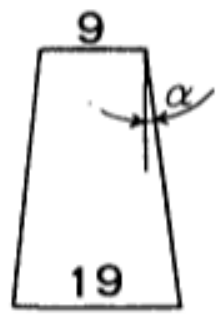

Fig. 1: Dimensions in $\mathrm{mm}$ of samples for the strain anneal technique, $\alpha \approx 6.5$ degrés.

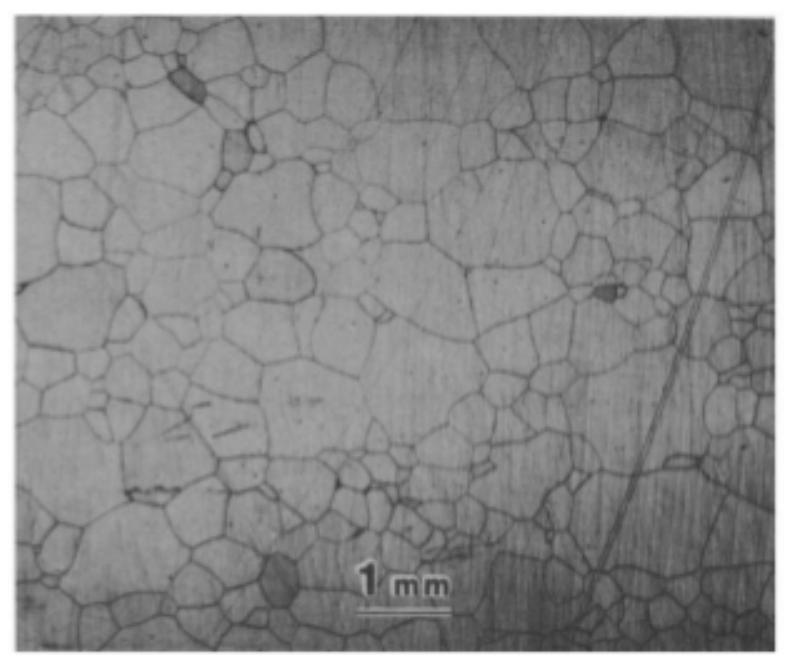

Fig. 2: Initial grain size after annealing at $450^{\circ} \mathrm{C}$ during 72 hours.

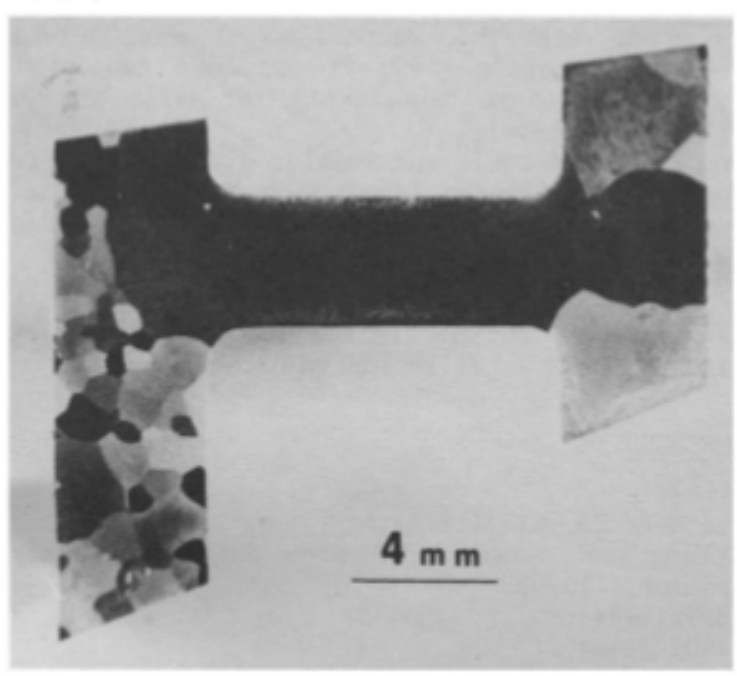

Fig. 3: Tensile single crystalline specimen cut in a tapered shape. Thickness: $2 \mathrm{~mm}$.

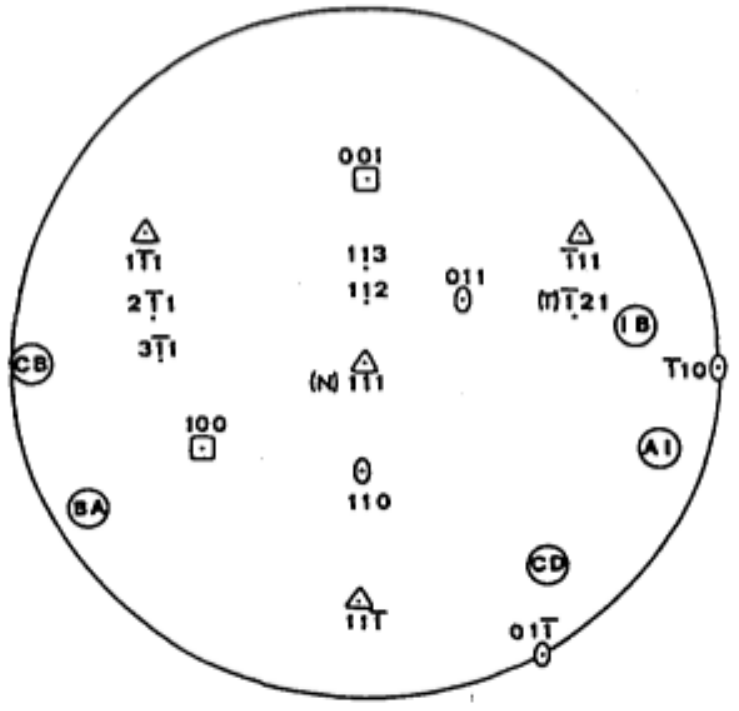

Fig. 4: Crystallographic orientation of specimens and thin foils. $T=[121]$ : tensile axis. $\mathrm{N}=[111]$ : thin foil normal. 


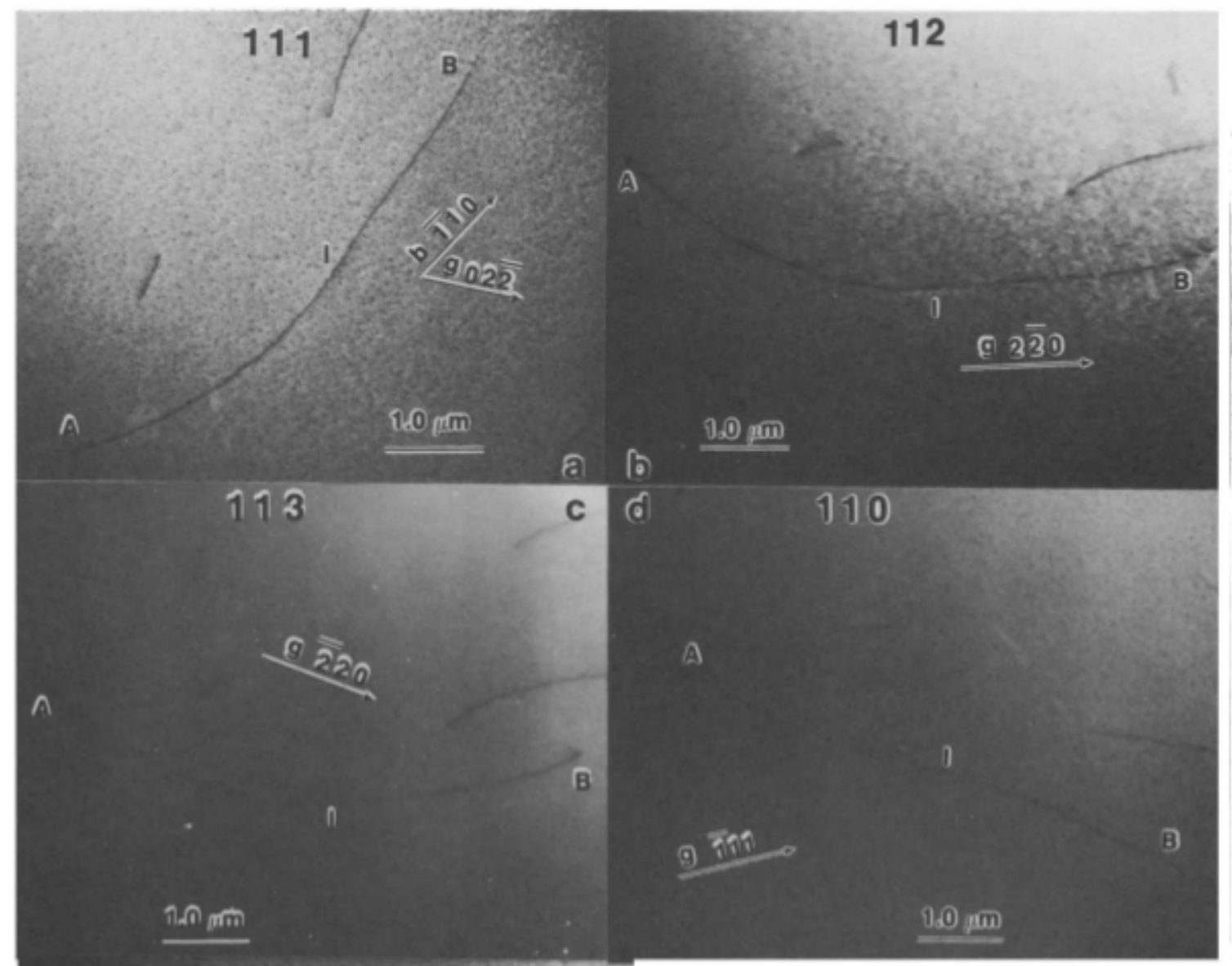

\section{1}

Fig. 5: Evidence of deviation between a compact plane and a non-compact plane.

a) Plate parallel to the thin foil.

b) and c) Plate parallel to possible planes

of the dislocations ( $A, I)$.

d) Evidence of deviation: the dislocation changes its curvature at I.

In $a, b, c$ and $d$ the bean directions are indicated. 


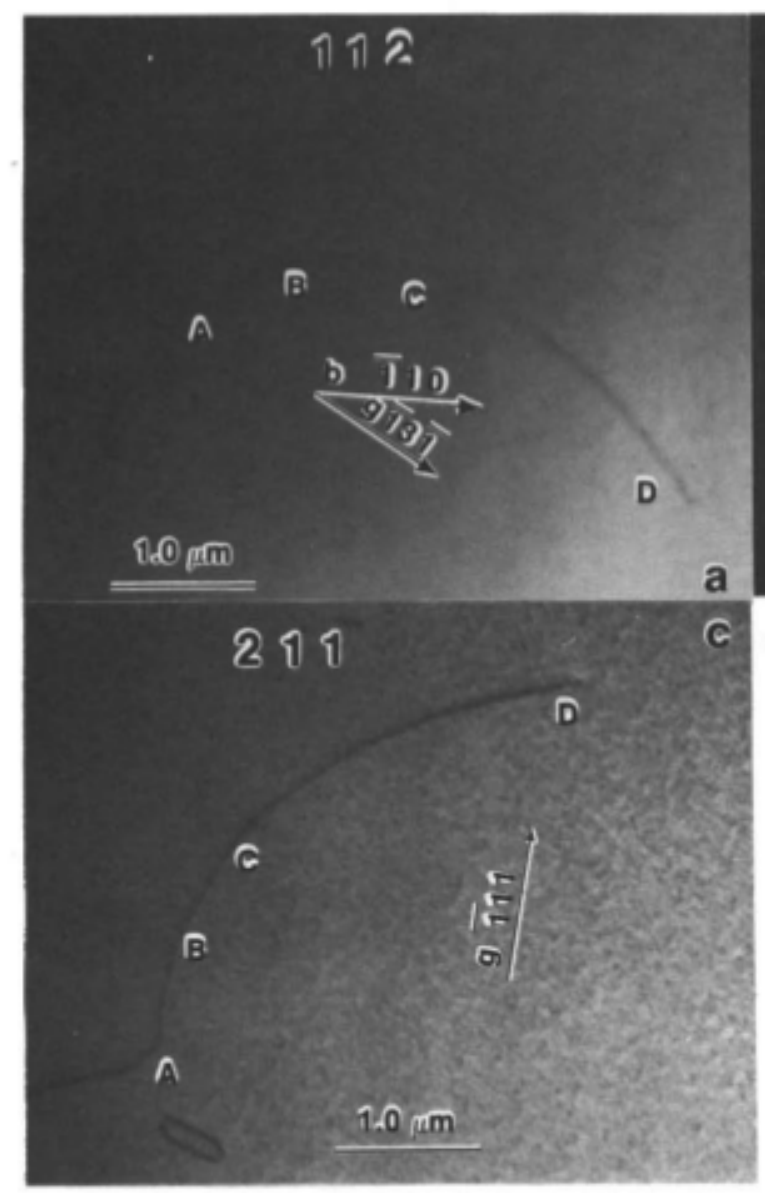

\section{กิกิ}

\section{c}

(B)

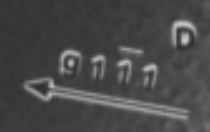

$\wedge$

ho

\section{กิด $\mathrm{mm}$}

Fig. 7: Curved dislocation in non-compact plane with a straight screw portion

a) Plate parallel to possible plane of the dislocation : (112)

b) and c) [121] and [211] orientations showing clearly that the screw portion $B C$ is straight.

\section{TABLE 1}

\section{กิก}

is

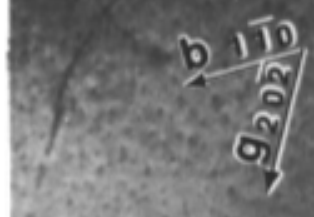

a

\section{$140 \mathrm{~mm}$}

Fig. 8: Dislocation in the (111) plane. Burgers vector $b=1 / 2[110]$. Bean direction [111].
Experimental Line Tension Local Stresses and Experimental Line Tension $\Delta \alpha=5$ deg. , $\frac{\Delta \rho}{\rho}=10 \%, \frac{\Delta \tau}{\tau}=15 \%, \frac{\Delta \mathrm{T}_{\mathrm{a}}}{\mathrm{T}_{\mathrm{a}}}=25 \%$

\begin{tabular}{|c|c|c|c|c|}
\hline$\alpha(d \bullet \theta)$ & $P \quad(\mathrm{gm})$ & $\left.\tau_{0} \mid M P p_{0}\right]$ & $\left.\tau_{*} \mid M P P_{*}\right]$ & $T_{0} \mid 0^{-0} \mathrm{NI}$ \\
\hline 25 & 4.5 & 2 & 2 & 26 \\
\hline 35 & 4 & 2 & 2 & 23 \\
\hline 45 & 3 & 2 & 2.2 & 1.7 \\
\hline
\end{tabular}

